\title{
Comparison of eddy covariance and modified Bowen ratio methods for measuring gas fluxes and implications for measuring fluxes of persistent organic pollutants
}

\author{
Damien Johann Bolinius ${ }^{1}$, Annika Jahnke ${ }^{1,2}$, and Matthew MacLeod ${ }^{1}$ \\ ${ }^{1}$ Department of Environmental Science and Analytical Chemistry (ACES), Stockholm University, \\ Svante Arrhenius väg 8, 114 18, Stockholm, Sweden \\ ${ }^{2}$ Department Cell Toxicology, Helmholtz Centre for Environmental Research (UFZ), Permoserstr. 15, \\ 04318 Leipzig, Germany
}

Correspondence to: Damien Johann Bolinius (damien.bolinius@aces.su.se)

Received: 7 September 2015 - Published in Atmos. Chem. Phys. Discuss.: 20 November 2015

Revised: 15 April 2016 - Accepted: 18 April 2016 - Published: 28 April 2016

\begin{abstract}
Semi-volatile persistent organic pollutants (POPs) cycle between the atmosphere and terrestrial surfaces; however measuring fluxes of POPs between the atmosphere and other media is challenging. Sampling times of hours to days are required to accurately measure trace concentrations of POPs in the atmosphere, which rules out the use of eddy covariance techniques that are used to measure gas fluxes of major air pollutants. An alternative, the modified Bowen ratio (MBR) method, has been used instead. In this study we used data from FLUXNET for $\mathrm{CO}_{2}$ and water vapor $\left(\mathrm{H}_{2} \mathrm{O}\right)$ to compare fluxes measured by eddy covariance to fluxes measured with the MBR method using vertical concentration gradients in air derived from averaged data that simulate the long sampling times typically required to measure POPs. When concentration gradients are strong and fluxes are unidirectional, the MBR method and the eddy covariance method agree within a factor of 3 for $\mathrm{CO}_{2}$, and within a factor of 10 for $\mathrm{H}_{2} \mathrm{O}$. To remain within the range of applicability of the MBR method, field studies should be carried out under conditions such that the direction of net flux does not change during the sampling period. If that condition is met, then the performance of the MBR method is neither strongly affected by the length of sample duration nor the use of a fixed value for the transfer coefficient.
\end{abstract}

\section{Introduction}

Despite the more than decade-old global ban on the production and use of persistent organic pollutants (POPs) such as polychlorinated biphenyls (PCBs), hexachlorobenzene and several organochlorine pesticides, these chemicals are still present in the environment and continue to raise concerns due to their persistence, bioaccumulation, toxicity and potential for long-range atmospheric transport (The Secretariat of the Stockholm Convention, 2010). As the production and use of POPs continues to decline, large cities, old stocks and revolatilization from soil are expected to become more important sources to the atmosphere (Nizzetto et al., 2010). Studying the sources and fate of organic pollutants in the environment is an important prerequisite to exposure and risk assessment; and environmental fate models that calculate fluxes of pollutants between air, water, soil, vegetation and other media have proven to be valuable tools in this respect (McKone and MacLeod, 2003). Measurements of fluxes of POPs emanating from source areas and between the atmosphere and other environmental media are needed to parameterize and evaluate the chemical fate models that are used as scientific support for international conventions on POPs (Gusev et al., 2012).

The preferred approach to measure the flux of major air pollutants between the earth's surface and the atmosphere is the eddy covariance (EC) technique (Baldocchi et al., 1988). The EC technique is based on measuring the covariance of the concentration of a pollutant and the vertical wind 
velocity, using data from very fast measurements (e.g. 5$10 \mathrm{~Hz}$ ). This approach works well for compounds such as $\mathrm{CO}_{2}$, methane, ozone and more recently also for mercury (Pierce et al., 2015), since concentrations can be measured at a high temporal resolution. However, it cannot be applied directly when studying trace-level organic micropollutants that require sampling times of a minimum of several hours when using active high-volume sampling, or even several weeks when using passive samplers (Hung et al., 2013).

One way to estimate chemical fluxes from measurements based on sampling times of hours to days is to use the modified Bowen ratio (MBR) method (Businger, 1986). The MBR method is based on the assumption that turbulent atmospheric transport occurs indiscriminately for chemicals, heat and other scalar quantities that can be described entirely by their magnitude without reference to direction. It can be used to measure the flux of a chemical pollutant $(x)$ from measurements of its concentration at two heights and the measured transfer coefficient of another scalar such as heat ( $y)$ over the same height interval (Meyers et al., 1996, Eq. 1):

$F_{x}=-K_{y} \cdot \frac{\Delta C_{x}}{\Delta Z}$,

where $F_{x}\left(\mathrm{ng} \mathrm{m}^{-2} \mathrm{~h}^{-1}\right)$ is the flux of chemical $x, K_{y}$ $\left(\mathrm{m}^{2} \mathrm{~h}^{-1}\right)$ is the measured eddy diffusion coefficient for scalar $y$ over the height interval $\Delta Z(\mathrm{~m})$ and $\Delta C_{x}\left(\mathrm{ng} \mathrm{m}^{-3}\right)$ is the measured concentration gradient of $x$ over the height interval. The negative sign on the right-hand side of the equation enforces the convention that downward fluxes have a negative sign, and upward fluxes a positive sign.

Among other applications, the MBR method has been used to measure volatilization fluxes of pesticides applied to agricultural fields (Majewski, 1999), to estimate PCB fluxes from Lake Superior to the overlying air (Rowe and Perlinger, 2012) and fluxes of polycyclic aromatic hydrocarbons (PAHs) above a forest canopy in Canada (Choi et al., 2008). In the study of Choi et al. (2008) air was sampled for $24 \mathrm{~h} \mathrm{ev-}$ ery 3 days at different heights for a period of 1 month while leaves in the forest canopy were developing. The samples were analyzed for PAHs and the data were combined with the eddy diffusivity of heat ( $K_{\text {heat }}$ ) determined from eddy covariance measurements from the FLUXNET network to estimate vertical PAH fluxes using the MBR method.

Our goal in this study was to test the limits of applicability of the MBR method and to evaluate its accuracy relative to the "standard" EC technique. We used data from the FLUXNET network to calculate fluxes of $\mathrm{CO}_{2}$ and water vapor $\left(\mathrm{H}_{2} \mathrm{O}\right)$ with the MBR method under different sampling duration scenarios and different assumptions about data availability for the eddy diffusion coefficient $K_{y}$. Thus, we took advantage of the high-frequency measurement data for $\mathrm{CO}_{2}$ and $\mathrm{H}_{2} \mathrm{O}$, and used them as proxies for organic micropollutants in order to analyze the performance of the MBR method compared to the EC method. By averaging the FLUXNET data over periods that ranged from $1 \mathrm{~h}$ to 1 week, we simulated sampling times that are typically required to measure POPs and other organic micropollutants in air. Our approach is similar to the one used by Majewski (1999), who simulated $24 \mathrm{~h}$ sampling periods from higher frequency data to characterize the potential for long sampling times to introduce error to the aerodynamic profiling method.

\section{Methods}

\subsection{Data sets}

All data used in this study can be accessed freely via the FLUXNET home page (http://fluxnet.ornl.gov/). A figure showing the flux tower and associated instruments can be found in the Supplement Fig. S1. The data set used in this study contains eddy flux parameters and micrometeorological measurements for the year 2009 taken at the Borden mixed deciduous forest site in Ontario, Canada (FLUXNET site code: CA-Cbo). A list of all parameters is given in Supplement Table S1. We selected measurements taken at heights of 33.3 and $40.7 \mathrm{~m}$. Air sampling in the study by Choi et al. (2008) was conducted at the same site in 2003 at heights of 29.1 and $44.4 \mathrm{~m}$.

Prior to any calculations, we filtered the data to remove about $25 \%$ of the observations that were flagged as unreliable for $\mathrm{CO}_{2}$ or $\mathrm{H}_{2} \mathrm{O}$. Details on the criteria for the flags can be found on the FLUXNET home page. Common reasons for flagging are instrument malfunctions, calibration problems and outliers. All flagged data were filtered out simultaneously, such that our analysis only includes data points collected at times when data were not flagged for either $\mathrm{CO}_{2}$ or $\mathrm{H}_{2} \mathrm{O}$.

On inspection of the distribution of the $\mathrm{CO}_{2}$ and $\mathrm{H}_{2} \mathrm{O}$ concentration gradients, it was apparent that a few outliers that had not been flagged could significantly alter the average gradient when pooling the data to simulate long sampling times. These outliers in some cases led to net flux estimations based on the MBR method that were in the opposite direction compared to the EC method. To exclude such outliers and reduce the influence of extreme values of measured parameters, the highest and lowest $2.5 \%$ of values of the $\mathrm{CO}_{2}$ gradient and the $\mathrm{H}_{2} \mathrm{O}$ gradient were removed from the data set prior to further calculations.

\subsection{Modified Bowen ratio}

We used $K_{\text {heat }}$ derived from EC flux measurements and measurements of the scalar temperature at two heights, as described in the paper by Choi et al. (2008) to specify the eddy diffusivity in the MBR method ( $K_{y}$ in Eq. 1). Specifically, $K_{\text {heat }}$ was inferred from the data set by first calculating the vertical turbulent flux of the sonic anemometer temperature $\overline{W^{\prime} T^{\prime}}\left(\mathrm{K} \mathrm{m} \mathrm{s}^{-1}\right.$, Eq. 2) from the turbulent sensible heat flux $\left(Q\right.$ in $\mathrm{W} \mathrm{m}^{-2}$ or $\left.\mathrm{J} \mathrm{s}^{-1} \mathrm{~m}^{-2}\right)$, using the air density $\left(\sigma_{\text {air }}\right.$ in $\left.\mathrm{kg} \mathrm{m}^{-3}\right)$ and the gravimetric heat capacity $\left(C_{\mathrm{p}}\right)$ of air 
measured at $33 \mathrm{~m}$ height $\left(1005.7 \mathrm{~J} \mathrm{~kg}^{-1} \mathrm{~K}^{-1}\right)$. Spurious $K_{\text {heat }}$ values less than or equal to zero were removed from the data set as these would indicate a heat flux against the measured temperature gradient.

$\overline{W^{\prime} T^{\prime}}=\frac{Q}{C_{\mathrm{p}} \cdot \sigma_{\text {air }}}$

$K_{\text {heat }}\left(\mathrm{m}^{2} \mathrm{~s}^{-1}\right)$ was then calculated based on temperatures measured at 40.7 and $33.3 \mathrm{~m}$ according to Eq. (3).

$K_{\text {heat }}=-\overline{W^{\prime} T^{\prime}} \frac{(40.7-33.3)}{\left(T_{40.7}-T_{33.3}\right)}$

Finally, vertical turbulent fluxes of $\mathrm{CO}_{2}$ and $\mathrm{H}_{2} \mathrm{O}$ were calculated using the MBR method and measured concentrations at 33 and $41.5 \mathrm{~m}$ averaged over different time intervals selected to represent sampling times typical for organic micropollutants, as described below. Fluxes calculated with the MBR method were compared with those measured by the EC method available from the FLUXNET data set.

\subsection{Data analysis}

To simulate sampling times typical for organic micropollutants, concentrations of $\mathrm{CO}_{2}$ and $\mathrm{H}_{2} \mathrm{O}$ reported as $30 \mathrm{~min}$ averages in the database were pooled and averaged over periods of 1, 2, 4, 8 and $24 \mathrm{~h}, 3$ days (72 h) and 1 week (168 h). Fluxes during four 2-month periods selected to represent each of the four seasons were then calculated from median values of these pooled data points during the entire period. Thus for example, fluxes calculated from $1 \mathrm{~h}$ simulated sampling times are based on the median of average vertical concentration gradients in $1 \mathrm{~h}$ pools measured at the same time each day over the entire 2 month period (see Fig. S2 for a visual representation). Medians were used instead of geometric means because of the presence of negative flux values. January and February represented winter, April and May spring, July and August summer and October and November fall.

We tested two approaches to specify $K_{\text {heat }}$ in the MBR method calculations. In the first approach, hourly average $K_{\text {heat }}$ values were calculated from $30 \mathrm{~min}$ averages of temperature measurements reported in the database. In the second approach, a geometric mean of $K_{\text {heat }}$ was calculated for all time points across the entire period corresponding to the simulated sampling time. The first approach takes advantage of the availability of high temporal resolution information about $K_{\text {heat }}$ at the FLUXNET site, but the second approach is likely to be common when applying the MBR since highfrequency meteorological data are not always available.

The direction of flux for $\mathrm{CO}_{2}$ can change on a diurnal basis (see Figs. 1 and S3). During the day, the flux of $\mathrm{CO}_{2}$ is often negative (i.e., downward) due to photosynthesis, while during the night, plant respiration produces $\mathrm{CO}_{2}$ and fluxes are positive (i.e. to the atmosphere). In addition, atmospheric conditions during the night are typically much more stable than during the day, resulting in a lack of large turbulent eddies and a higher contribution of additional transport mechanisms, such as horizontal advection, to the total flux. The result is that fluxes measured using EC during the night are often underestimated (Aubinet, 2008).

To understand the impact of changing directions of flux and to investigate potential underestimation of flux at night, fluxes during the day and during the night calculated with the MBR method were evaluated against EC measurements separately. Nighttime data were set to cover from 21:00 to 05:00 local time across all seasons, and daytime data were set from 09:00 to 17:00 local time. The nighttime/daytime divisions were selected based on the shortest interval between sunrise and sunset at the site. The $8 \mathrm{~h}$ periods representing day and night allowed us to construct $24 \mathrm{~h}, 3$ day and 1 week sampling periods by averaging a whole number of $8 \mathrm{~h}$ periods taken at the same time of day over multiple days. In addition to the nighttime/daytime split data, we also examined the performance of the MBR method relative to the EC method when using continuous data that ignored day/night differences.

\section{Results}

\section{1 $\quad K_{\text {heat }}$ and concentration gradients}

Our calculated $K_{\text {heat }}$ values (Fig. 1) are in good agreement with values for the same site during the same time of year in 2003 (Choi et al., 2008, shown in Fig. S4). Values are close to 0 during the night and in the range of 0.0026 to $35.8 \mathrm{~m}^{2} \mathrm{~s}^{-1}$ during the day over the summer period, with $95 \%$ of the values between 0.029 and $22.11 \mathrm{~m}^{2} \mathrm{~s}^{-1}$.

The fluxes calculated with the MBR method are proportional to the product of $K_{\text {heat }}$ and the concentration gradient of either $\mathrm{CO}_{2}$ or $\mathrm{H}_{2} \mathrm{O}$ (Eq. 1). The raw data at $30 \mathrm{~min}$ time resolution that were pooled and used to calculate the fluxes with the MBR method are visualized in Fig. 1.

\subsection{Performance of the MBR method on continuous time series}

When used with continuous time series, fluxes measured with the MBR method are often not of the right magnitude and/or direction for $\mathrm{CO}_{2}$ relative to the "reference" EC data (see a representative example in Fig. 2). Inspection of the results indicated that the MBR method would fail when the direction of the flux of $\mathrm{CO}_{2}$ changed during the simulated sampling period. Based on this result, we focused our analysis on comparing the performance of the MBR method to the EC method only during the day or only during the night when fluxes are generally unidirectional. 


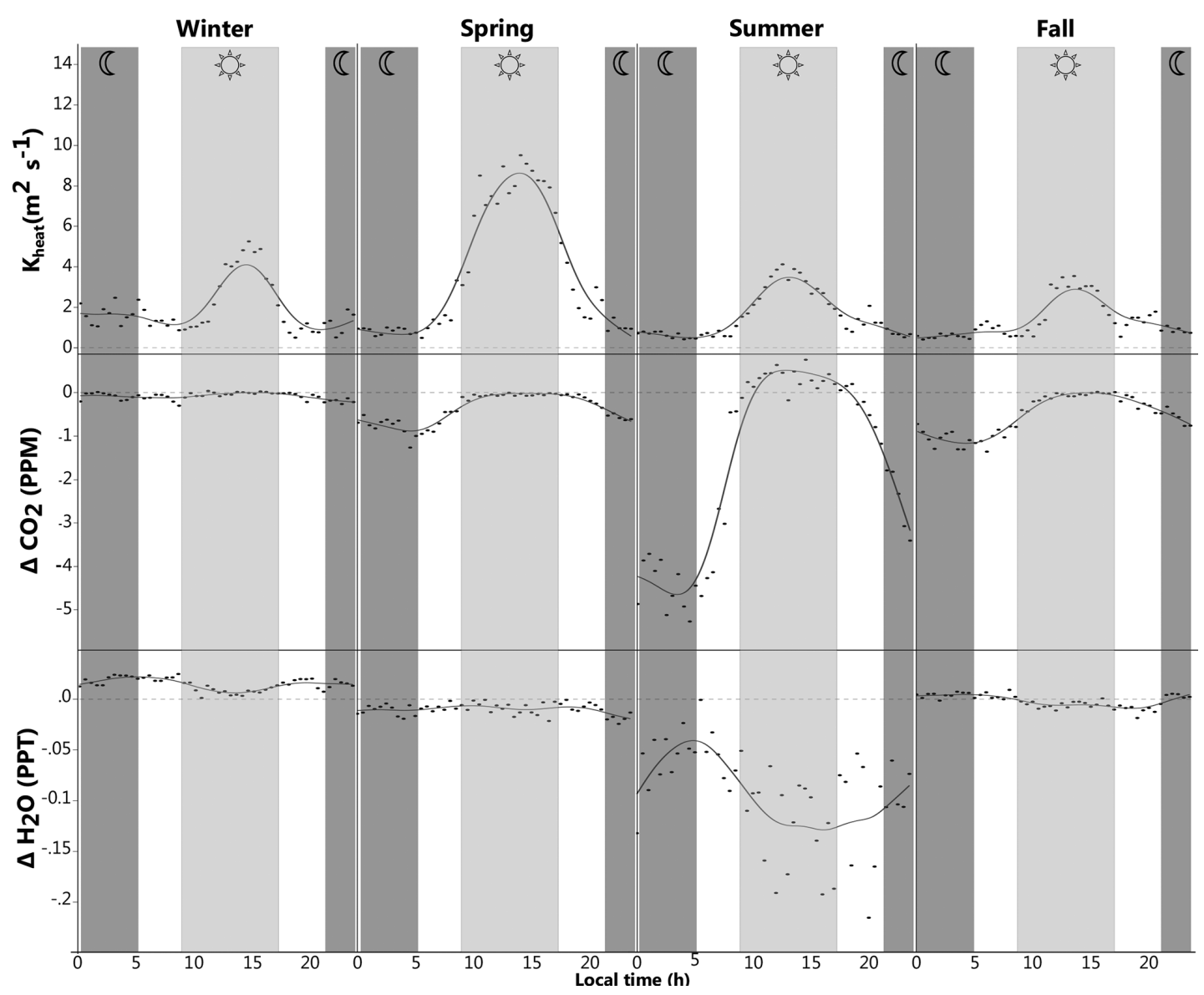

Figure 1. Half-hourly averages of $K_{\text {heat }}$ and the concentration gradients of $\mathrm{CO}_{2}$ and $\mathrm{H}_{2} \mathrm{O}$ across the different seasons (concentration at $40.7 \mathrm{~m}$ - concentration at $33.3 \mathrm{~m}$ ). The dotted line indicates 0 in all plots; the grey areas indicate the $8 \mathrm{~h}$ periods representing day and night.

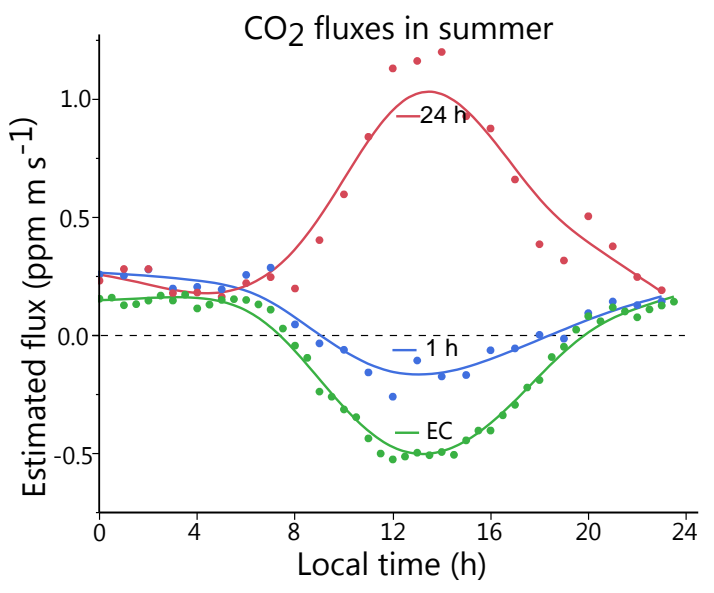

Figure 2. A comparison of measured fluxes using the modified Bowen ratio (MBR) method ( 1 and $24 \mathrm{~h}$ pooled data using hourly $K_{\text {heat }}$ values) with the eddy covariance (EC) measurements. The simulated $24 \mathrm{~h}$ sampling time includes a change in the direction of the $\mathrm{CO}_{2}$ flux, which results in a measured flux with the MBR method that has the wrong direction and magnitude.

\subsection{Performance of the MBR method with hourly resolved and fixed values of $K_{\text {heat }}$}

The use of either hourly resolved data for $K_{\text {heat }}$ or a fixed value did not significantly affect the MBR method. A student $t$ test comparing the similarity of the two data sets resulted in a $P$ value below 0.0001 .

Results using a fixed value for $K_{\text {heat }}$ are shown in Table 1; those using hourly resolved data for $K_{\text {heat }}$ are given in Supplement Table S2.

\subsection{Performance of the MBR method on day/night split data}

Fluxes of $\mathrm{CO}_{2}$ during the nighttime only, measured using the MBR method in combination with simulated sampling times ranging from $1 \mathrm{~h}$ to 1 week, are a factor of 1.7 and up to a factor of 2.1 larger on average than those derived with the EC method (see Table 1). Fluxes of $\mathrm{CO}_{2}$ during the daytime only, measured using the MBR method have, in some cases, the opposite sign of the fluxes reported using the EC technique. Specifically, the MBR method produces daytime 
Table 1. Cumulative fluxes for $8 \mathrm{~h}$ periods representing day and night across the 2 month periods representing spring, summer, fall and winter. Fluxes measured by the MBR method that are in the opposite direction to those measured by the EC method are marked with "(!)". Positive fluxes are defined as fluxes moving upwards from the canopy. The ratio of MBR results over EC results is based on the geometric mean of the MBR results divided by the EC result. The MBR fluxes for the 1 week sampling period were left out in the calculation of the geometric mean during the day in winter for $\mathrm{CO}_{2}$ and during the night in fall for $\mathrm{H}_{2} \mathrm{O}$. This table shows fluxes calculated with a fixed value for $K_{\text {heat }}$.

\begin{tabular}{|c|c|c|c|c|c|c|c|c|c|}
\hline \multicolumn{2}{|l|}{$\mathrm{CO}_{2}(\mathrm{PPM} \mathrm{m})$} & \multicolumn{2}{|c|}{ Spring } & \multicolumn{2}{|c|}{ Summer } & \multicolumn{2}{|r|}{ Fall } & \multicolumn{2}{|c|}{ Winter } \\
\hline & & Day & Night & Day & Night & Day & Night & Day & Night \\
\hline \multicolumn{2}{|l|}{ Eddy covariance } & -0.332 & 0.295 & -3.360 & 1.071 & 0.074 & 0.227 & 0.189 & 0.112 \\
\hline \multirow{7}{*}{ Modified Bowen ratio, constant $K_{\text {heat }}$} & $1 / \mathrm{h}$ & $0.275(!)$ & 0.408 & -1.202 & 1.529 & 0.073 & 0.390 & 0.163 & 0.224 \\
\hline & $1 / 2 \mathrm{~h}$ & $0.313(!)$ & 0.434 & -1.124 & 1.703 & 0.113 & 0.421 & 0.187 & 0.196 \\
\hline & $1 / 4 \mathrm{~h}$ & $0.319(!)$ & 0.413 & -1.107 & 1.544 & 0.067 & 0.396 & 0.163 & 0.199 \\
\hline & $1 / 8 \mathrm{~h}$ & $0.250(!)$ & 0.441 & -1.000 & 1.697 & 0.093 & 0.392 & 0.159 & 0.159 \\
\hline & $1 /$ day & $0.353(!)$ & 0.466 & -1.064 & 2.602 & 0.145 & 0.527 & 0.176 & 0.185 \\
\hline & $1 / 3$ days & $0.335(!)$ & 0.658 & -0.991 & 2.258 & 0.138 & 0.618 & 0.096 & 0.185 \\
\hline & $1 /$ week & $0.409(!)$ & 0.459 & -1.114 & 2.576 & 0.136 & 0.621 & $-0.019(!)$ & 0.032 \\
\hline MBR/EC method & & $-0.960(!)$ & 1.566 & 0.323 & 1.811 & 1.425 & 2.071 & 0.893 & 1.317 \\
\hline \multirow{2}{*}{\multicolumn{2}{|c|}{$\mathrm{H}_{2} \mathrm{O}(\mathrm{PPT} \mathrm{m})$}} & \multicolumn{2}{|c|}{ Spring } & \multicolumn{2}{|c|}{ Summer } & \multicolumn{2}{|c|}{ Fall } & \multicolumn{2}{|c|}{ Winter } \\
\hline & & Day & Night & Day & Night & Day & Night & Day & Night \\
\hline \multicolumn{2}{|l|}{ Eddy covariance } & 0.420 & 0.016 & 1.118 & 0.038 & 0.180 & 0.005 & 0.049 & 0.001 \\
\hline \multirow{7}{*}{ Modified Bowen ratio, constant $K_{\text {heat }}$} & $1 / \mathrm{h}$ & 0.048 & 0.006 & 0.243 & 0.027 & 0.011 & $-0.001(!)$ & $-0.007(!)$ & $-0.009(!)$ \\
\hline & $1 / 2 \mathrm{~h}$ & 0.052 & 0.006 & 0.236 & 0.030 & 0.009 & $-0.001(!)$ & $-0.007(!)$ & $-0.008(!)$ \\
\hline & $1 / 4 \mathrm{~h}$ & 0.040 & 0.007 & 0.265 & 0.032 & 0.008 & $-0.001(!)$ & $-0.006(!)$ & $-0.007(!)$ \\
\hline & $1 / 8 \mathrm{~h}$ & 0.033 & 0.009 & 0.239 & 0.030 & 0.008 & $-0.001(!)$ & $-0.008(!)$ & $-0.008(!)$ \\
\hline & $1 /$ day & 0.029 & 0.009 & 0.269 & 0.044 & 0.007 & $-0.001(!)$ & $-0.004(!)$ & $-0.011(!)$ \\
\hline & $1 / 3$ days & 0.046 & 0.012 & 0.332 & 0.050 & 0.010 & $-0.003(!)$ & $-0.015(!)$ & $-0.015(!)$ \\
\hline & $1 /$ week & 0.061 & 0.007 & 0.323 & 0.038 & 0.014 & 0.001 & $-0.009(!)$ & $-0.014(!)$ \\
\hline MBR/EC method & & 0.102 & 0.464 & 0.241 & 0.915 & 0.052 & $-0.169(!)$ & $-0.149(!)$ & $-9.305(!)$ \\
\hline
\end{tabular}

fluxes with the opposite sign compared to the EC method during the spring and for the 1 week duration simulated sampling scenario in the winter (values marked with "(!)" in Table 1). In those cases where the direction of flux calculated with the MBR does not agree with the EC method, the disagreement is attributable to the median value of $\Delta \mathrm{CO}_{2}$ (between 41.5 and $33 \mathrm{~m}$ ) selected to represent the sampling period, with a sign that implies a flux in the opposite direction of the flux measured with the EC method.

In cases where the direction of daytime flux measured using the MBR method agreed with the EC method, the ratio of the two fluxes ranged from 0.32 to 1.4 , implying that the two methods differed by factors that range from 1.4 to 3.0 and that the MBR method may either underestimate or overestimate fluxes relative to the EC method.

For $\mathrm{H}_{2} \mathrm{O}$, the fluxes measured with the MBR method are in the same direction as those measured by the EC method during spring, summer and during the day in the fall. When the two methods agree about the direction of flux, the ratio of fluxes measured by the MBR method to the EC method is between 0.9 and 0.052 , implying differences between the methods by factors of 1.1 to 20 , and that fluxes of $\mathrm{H}_{2} \mathrm{O}$ are underestimated if the MBR method is applied as compared to the EC method. Fluxes measured during the winter season with the MBR method are negative (i.e., from the atmosphere to the surface), while the EC method indicates fluxes are positive (i.e., from the surface to the atmosphere). Fluxes measured by both methods during the night in the fall are small, with an upward flux measured using the EC method and downward fluxes measured by the MBR method in all cases except the longest 1 week simulated sampling period.

In general, the fluxes measured using the two different methods are in better agreement for $\mathrm{CO}_{2}$ than for $\mathrm{H}_{2} \mathrm{O}$ (Table 1). It is interesting to note that the MBR method generally overestimates the flux of $\mathrm{CO}_{2}$ relative to the $\mathrm{EC}$ method, while it underestimates fluxes of $\mathrm{H}_{2} \mathrm{O}$ in most cases.

\section{Discussion}

The MBR method fails for $\mathrm{CO}_{2}$ when using continuous time series in cases where the simulated sampling period encompasses the shift between night and day, and there is also a shift from upward fluxes (dominated by respiration) at night to downward fluxes (dominated by photosynthesis) during daytime. As shown in Eq. (3), the flux estimated using the MBR method only depends on $K_{\text {heat }}$ and the vertical con- 
centration gradient for the compound of interest. The error arises because the average values of $K_{\text {heat }}$ are dominated by high values that occur during the day, while average values of $\triangle \mathrm{CO}_{2}$ are dominated by extreme values that occur at night (see especially the summer season for $\mathrm{CO}_{2}$ in Fig. 1 and data for $\mathrm{CO}_{2}$ in the summer visualized in Fig. S5).

The $\mathrm{CO}_{2}$ fluxes determined using the MBR method during the daytime for the spring season and when simulating a sampling time of 1 week during daytime for the winter were in the opposite direction relative to the fluxes determined using the EC method. During spring this could be caused by a reversal of the direction of flux due to the development of leaves and the start of photosynthesis taking place halfway through the season, which would produce a shift from a continuous net flux of $\mathrm{CO}_{2}$ out of the canopy to a diel cycle of $\mathrm{CO}_{2}$ uptake and release. Furthermore, it is possible that the simulated 1 week sampling duration during daytime in the winter might have encompassed periods when the net direction of flux of $\mathrm{CO}_{2}$ changed, due to the movement of air masses with variable $\mathrm{CO}_{2}$ concentrations across the region. Thus, all of the cases of disagreement between the MBR method and the EC method about the direction of flux of $\mathrm{CO}_{2}$ that are shown in Table 2 might be attributable to applying the MBR method using simulated sampling times that encompass a change of direction of the net flux.

In general, the duration of simulated sampling does not have a strong influence on the fluxes measured with the MBR method. Exceptions are the longest simulated sampling times during the daytime in winter for $\mathrm{CO}_{2}$ and during nighttime in the fall for $\mathrm{H}_{2} \mathrm{O}$. We simulated sampling times of $24 \mathrm{~h}$, 3 days and 1 week by combining data that were measured over non-consecutive $8 \mathrm{~h}$ periods during 2 month time windows selected to represent the four seasons. For the 3 day and 1 week simulated sampling times there are just three to four data points per season, depending on the data availability, which may introduce higher uncertainty in the median value used in our MBR method calculations compared to the shorter simulated sampling times.

For $\mathrm{H}_{2} \mathrm{O}$, which nearly always has a net flux moving upwards from the canopy during both the day and the night, pooling of the data over longer time intervals and application of the MBR method also led to estimations of the direction of flux that were opposite to the EC method in the winter and fall seasons. In winter, fluxes of $\mathrm{H}_{2} \mathrm{O}$ measured by the EC method were small and moving upwards, while those calculated with the MBR method were small and moving downwards (Table 2). A recent study focusing on drainage basins in Canada reported low but positive fluxes of water vapor during the winter season (Wang et al., 2014), which is consistent with measurements using the EC method. In this case we traced the origin of the different directions of flux calculated with the MBR method relative to the EC method to differences in $\mathrm{H}_{2} \mathrm{O}$ concentration gradients across different height intervals. Reported fluxes of $\mathrm{H}_{2} \mathrm{O}$ using the EC method were measured at $33.3 \mathrm{~m}$, while for the MBR method we used a gradient of concentrations measured at 41.5 and $33 \mathrm{~m}$. During the winter for $\mathrm{H}_{2} \mathrm{O}$ there was a clear discrepancy between gradients measured at these heights and between 33 and $25.7 \mathrm{~m}$, with the latter being more consistent with the EC measurements (Fig. S6). The cold and low humidity during the winter in Canada might play a role here as discrepancies between the concentration gradients of $\mathrm{H}_{2} \mathrm{O}$ at different heights were only observed in the winter and to a lesser extent in the fall.

It is clear from our analysis that a requirement for the MBR method to give accurate results for prolonged sampling times is to only sample during a time period when the chemicals of interest are expected to have a unidirectional flux. The occurrence of a day/night regime has implications for designing sampling campaigns for organic pollutants that require sampling times longer than the $8 \mathrm{~h}$ intervals with stable conditions chosen as daytime or nighttime above, and which may exhibit changes in the direction of flux between daytime and nighttime periods. This can be the case for many POPs, and the direction of fluxes can be estimated using appropriately parameterized dynamic chemical multimedia fate models (see, for example, Gasic et al., 2010). When longer sampling times are needed, samples could be pooled by sampling at the same time of day during consecutive $24 \mathrm{~h}$ periods as was simulated here by combining data from selected $8 \mathrm{~h}$ periods.

When sampling over time periods of several hours to several days, as simulated in this study, it is very likely that steady-state conditions during the sampling period are not achieved. Our results indicate however that when fluxes were unidirectional, measurements using the MBR method were usually within 1 order of magnitude of those from the EC method, and that in most cases the difference was less than a factor of 4 . The summer period, in which $K_{\text {heat }}$ is low and the gradients of $\mathrm{CO}_{2}$ and $\mathrm{H}_{2} \mathrm{O}$ are large due to stable atmospheric conditions, showed the best agreement between the MBR and EC methods. In the study of Choi et al. (2008), they estimated that their uncertainty in fluxes of PAHs derived from the MBR method was an order of magnitude, which is within the range of agreement we obtained between the MBR method and the EC method.

Fluxes measured with the MBR method corresponded better with the $\mathrm{EC}$ data for $\mathrm{CO}_{2}$ than for $\mathrm{H}_{2} \mathrm{O}$, the reason for which is unknown. However our investigation of the discrepancy in direction of flux between the two methods for $\mathrm{H}_{2} \mathrm{O}$ in the winter suggests that the concentration gradient of $\mathrm{H}_{2} \mathrm{O}$ is more variable over height than that of $\mathrm{CO}_{2}$. Therefore the gradient that we selected between 41.5 and $33 \mathrm{~m}$ may be more representative of the flux measured at $33.3 \mathrm{~m}$ with the EC method for $\mathrm{CO}_{2}$ than for $\mathrm{H}_{2} \mathrm{O}$.

In general, the variation between fluxes determined using the MBR method for different sampling frequencies was small, suggesting that longer sampling times did not introduce a higher bias relative to EC measurements. Using a single value for $K_{\text {heat }}$, in this case the geometric mean across 
the sampling period, was found to be a good substitute for hourly $K_{\text {heat }}$ values, indicating that it is possible to use the MBR method when there are no high-frequency data available for the transfer coefficient.

Some studies have shown that additional transport mechanisms aside from eddy diffusion, such as advection, can become more important during night, thereby violating the conditions needed for EC measurements to take place, and resulting in underestimations of the night time fluxes (Aubinet, 2008). In this study, there is no clear difference in the performance of the two methods relative to one another during either day or night. We note however that the MBR method relies on $K_{\text {heat }}$ determined under the assumption that only turbulent atmospheric processes occur, so the effect of additional transport mechanisms might not be evident in our analysis.

Based on the findings in this study it is clear that field studies that use the MBR method to measure gas fluxes of POPs and other organic micropollutants should be designed such that the direction of the flux does not change during the sampling period. If this condition is fulfilled and the concentration gradients are large enough to be measured accurately, then we find no strong evidence that the duration of sample collection affects the performance of the MBR method. Furthermore, using a fixed value for the transfer coefficient instead of hourly data is a good alternative that should not introduce a significant bias when there are no high-frequency data available.

Relaxed eddy accumulation (REA) is another method that is used to measure fluxes of chemicals for which the EC approach is not feasible. Unlike the MBR method, REA only samples air at one height but uses fast switching valves in combination with high-frequency measurements of the wind speed and direction to split the incoming airflow according to the prevailing vertical wind direction (Businger and Oncley, 1990). The air can then be collected in bags or other reservoirs (Pattey et al., 1993) for further analyses or be passed through denuders or sorbents such as polyurethane foam (Majewski et al., 1993) as is done with conventional high-volume sampling to accumulate the levels needed for analysis. To our knowledge, the REA method has not seen any recent uses to measure the fluxes of POPs or POP-like pollutants, unlike the MBR method which has seen an increasing number of applications in recent years. The likely reason is that it is technically more demanding to set up the REA, and it requires specialized equipment.

There is a wide scope for applying the MBR method to measure fluxes of POPs and POP-like chemicals in the atmosphere. A key data gap for many POPs is a lack of measurements of the fluxes of POPs from dispersed sources to the atmosphere (McKone and MacLeod, 2003); and the studies by Rowe and Perlinger (2012) for PCBs from the Hudson river, by Perlinger et al. (2005) for HCHs and hexachlorobenzene over Lake Superior and by Kurt-Karakus et al. (2006) with treated soils demonstrate that the MBR method could help fill that gap.

The MBR method could also be used to measure fluxes of POPs in depositional areas, such as forests as shown by the study of Choi et al. (2008), or in source areas such as large cities where recent studies of vertical concentration gradients of POPs did not lead to quantitative flux estimates ( $\mathrm{Li}$ et al., 2009; Moreau-Guigon et al., 2007). Our results reported in this paper imply that measurements of fluxes of POPs could be accomplished using the MBR method with passive air samplers instead of the active samplers that have been used in these studies so far, as long as the direction of the flux does not change during the sampling period and the concentration gradients are large enough to be measured.

\section{The Supplement related to this article is available online at doi:10.5194/acp-16-5315-2016-supplement.}

Author contributions. Matthew MacLeod had the idea for this study, Damien Johann Bolinius and Matthew MacLeod designed the study and Damien Johann Bolinius gathered the data, performed the analysis and prepared the manuscript with contributions from Annika Jahnke and Matthew MacLeod.

Acknowledgements. We thank Frank Wania for constructive suggestions during the early phases of this work. This research was funded by the Swedish Research Council Vetenskapsrådet (VR), project number 2011-3890, "Investigating thermodynamic controls on the cycling of persistent organic chemicals in forest systems".

Edited by: R. Ebinghaus

\section{References}

Aubinet, M.: Eddy covariance $\mathrm{CO}_{2}$ flux measurements in nocturnal conditions: an analysis of the problem, Ecol. Appl., 18, 13681378, doi:10.1890/06-1336.1, 2008.

Baldocchi, D. D., Hincks, B. B., and Meyers, T. P.: Measuring biosphere-atmosphere exchanges of biologically related gases with micrometeorological methods, Ecology, 69, 1331, doi:10.2307/1941631, 1988.

Businger, J. A.: Evaluation of the accuracy with which dry deposition can be measured with current micrometeorological techniques, J. Clim. Appl. Meteorol., 25, 1100-1124, doi:10.1175/1520-0450(1986)025<1100:EOTAWW>2.0.CO;2, 1986.

Businger, J. A. and Oncley, S. P.: Flux measurement with conditional sampling, J. Atmos. Ocean. Tech., 7, 349-352, doi:10.1175/1520-0426(1990)007<0349:FMWCS>2.0.CO;2, 1990. 
Choi, S.-D., Staebler, R. M., Li, H., Su, Y., Gevao, B., Harner, T., and Wania, F.: Depletion of gaseous polycyclic aromatic hydrocarbons by a forest canopy, Atmos. Chem. Phys., 8, 4105-4113, doi:10.5194/acp-8-4105-2008, 2008.

Gasic, B., MacLeod, M., Scheringer, M., and Hungerbuhler, K.: Assessing the impact of weather events at mid-latitudes on the atmospheric transport of chemical pollutants using a 2dimensional multimedia meteorological model, Atmos. Environ., 44, 4489-4496, doi:10.1016/j.atmosenv.2010.07.016, 2010.

Gusev, A., MacLeod, M., and Bartlett, P.: Intercontinental transport of persistent organic pollutants: A review of key findings and recommendations of the task force on hemispheric transport of air pollutants and directions for future research, Atmospheric Pollut. Res., 3, 463-465. doi:10.5094/APR.2012.053, 2012.

Hung, H., MacLeod, M., Guardans, R., Scheringer, M., Barra, R., Harner, T., and Zhang, G.: Toward the next generation of air quality monitoring: Persistent organic pollutants, Atmos. Environ., 80, 591-598, doi:10.1016/j.atmosenv.2013.05.067, 2013.

Kurt-Karakus, P. B., Bidleman, T. F., Staebler, R. M., and Jones, K. C.: Measurement of DDT fluxes from a historically treated agricultural oil in Canada, Environ. Sci. Technol., 40, 4578-4585, doi:10.1021/es060216m, 2006.

Li, Y., Zhang, Q., Ji, D., Wang, T., Wang, Y., Wang, P., Ding, L., and Jiang, G.: Levels and vertical distributions of PCBs, PBDEs, and OCPs in the atmospheric boundary layer: Observation from the Beijing 325-m meteorological tower, Environ. Sci. Technol., 43, 1030-1035, 2009.

Majewski, M., Desjardins, R., Rochette, P., Pattey, E., Seiber, J., and Glotfelty, D.: Field comparison of an eddy accumulation and an aerodynamic-gradient system for measuring pesticide volatilization fluxes, Environ. Sci. Technol., 27, 121-128, doi:10.1021/es00038a012, 1993.

Majewski, M. S.: Micrometeorologic methods for measuring the post-application volatilization of pesticides, Water. Air Soil Pollut., 115, 83-113, doi:10.1023/A:1005297121445, 1999.

McKone, T. E. and MacLeod, M.: Tracking multiple pathways of human exposure to persistent multimedia pollutants: Regional, continental and global-scale models, Annu. Rev. Env. Resour., 28, 463-492, doi:10.1146/annurev.energy.28.050302.105623, 2003.

Meyers, T. P., Hall, M. E., Lindberg, S. E., and Kim, K.: Use of the modified Bowen-ratio technique to measure fluxes of trace gases, Atmos. Environ., 30, 3321-3329, doi:10.1016/13522310(96)00082-9, 1996.
Moreau-Guigon, E., Motelay-Massei, A., Harner, T., Pozo, K., Diamond, M., Chevreuil, M., and Blanchoud, H.: Vertical and temporal distribution of persistent organic pollutants in Toronto. 1. Organochlorine Pesticides, Environ. Sci. Technol., 41, 2172 2177, doi:10.1021/es062705s, 2007.

Nizzetto, L., MacLeod, M., Borgå, K., Cabrerizo, A., Dachs, J., Guardo, A. D., Ghirardello, D., Hansen, K. M., Jarvis, A., Lindroth, A., Ludwig, B., Monteith, D., Perlinger, J. A., Scheringer, M., Schwendenmann, L., Semple, K. T., Wick, L. Y., Zhang, G., and Jones, K. C.: Past, present, and future controls on levels of persistent organic pollutants in the global environment, Environ. Sci. Technol., 44, 6526-6531, doi:10.1021/es100178f, 2010.

Pattey, E., Desjardins, R. L., and Rochette, P.: Accuracy of the relaxed eddy-accumulation technique, evaluated using $\mathrm{CO}_{2}$ flux measurements, Bound.-Lay. Meteorol., 66, 341-355, doi:10.1007/BF00712728, 1993.

Perlinger, J. A., Tobias, D. E., Morrow, P. S., and Doskey, P. V.: Evaluation of novel techniques for measurement of air-water exchange of persistent bioaccumulative toxicants in Lake Superior, Environ. Sci. Technol., 39, 8411-8419, doi:10.1021/es050899q, 2005.

Pierce, A. M., Moore, C. W., Wohlfahrt, G., Hörtnagl, L., Kljun, N., and Obrist, D.: Eddy covariance flux measurements of gaseous elemental mercury using cavity ring-down spectroscopy, Environ. Sci. Technol., 49, 1559-1568, doi:10.1021/es505080z, 2015.

Rowe, M. D. and Perlinger, J. A.: Micrometeorological measurement of hexachlorobenzene and polychlorinated biphenyl compound air-water gas exchange in Lake Superior and comparison to model predictions, Atmos. Chem. Phys., 12, 4607-4617, doi:10.5194/acp-12-4607-2012, 2012.

The Secretariat of the Stockholm Convention: Stockholm convention on persistent organic pollutants (POPs) as amended in 2009, http://chm.pops.int/TheConvention/Overview/ TextoftheConvention/tabid/2232/Default.aspx (last access: 16 of August 2015), 2010.

Wang, S., Huang, J., Li, J., Rivera, A., McKenney, D. W., and Sheffield, J.: Assessment of water budget for sixteen large drainage basins in Canada, J. Hydrol., 512, 1-15, doi:10.1016/j.jhydrol.2014.02.058, 2014. 